\title{
O corpo desviante: experiência de nascimento de crianças com microcefalia por Zika Vírus ${ }^{1}$
}

\author{
Gênesis Vivianne Soares Ferreira Cruz $^{2}$ \\ Reni Barsaglini 3 \\ Universidade Federal de Mato Grosso
}

Resumo: É oportuno compreender como as pessoas interpretam e agem diante do nascimento de uma criança com microcefalia por Zika vírus dada sua ampla divulgação no meio social, onde circulam informações que a todo tempo são atualizadas pelas novas descobertas que cercam, ainda, os enigmas do surgimento e da distribuição desse agravo. Nesses cenários se mobilizam experiências individuais e coletivas, exprimindo vivências complexas, principalmente, quando envolve a deficiência física, não há possibilidades de cura e exigem esforços para o gerenciamento contínuo.

Palavras-chave: corpo; experiência; microcefalia; Zika vírus.

\footnotetext{
${ }^{1}$ O presente estudo é um recorte do Projeto Matricial intitulado "Microcefalia: estudo qualitativo de experiência de condição crônica”, devidamente registrado sob o no PROPEq-UFMT 408/2016.

2 Possui graduação em Licenciatura Plena em Ciências Biológicas pela Universidade Federal de Mato Grosso (2005) e graduação em Enfermagem e Obstetrícia pela UFMT (2008). Tem especialização na área de Saúde Pública, com ênfase em Saúde da Família pela Faculdade de Cuiabá (2008). Especialista em Enfermagem em Pediatria e Cuidados Intensivos Neonatais, da Faculdade Pequeno Príncipe/Curitiba (2018). Mestre e Doutora em Enfermagem pelo Programa de Pósgraduação de Enfermagem da UFMT (2011 e 2019). Professora Adjunta III da Faculdade de Enfermagem da UFMT, campus Cuiabá. Membro do Grupo de Pesquisa: Saúde, Experiência, Cultura e Sociedade (SECS) e do Grupo de Estudos em Saúde da Criança e do Adolescente (GESCA).

3 Graduada em Pedagogia pela Universidade Estadual Paulista Júlio de Mesquita Filho (1992), especialista em Saúde Pública pela Universidade Federal de São Carlos e em Política de recursos humanos para a gestão do SUS pela Universidade de Brasília. Concluiu mestrado em Saúde e Ambiente pela Universidade Federal de Mato Grosso (1999), doutorado em Saúde Coletiva pela Universidade Estadual de Campinas (2006) e pós-doutorado no Centro de Estudos Sociais da Universidade de Coimbra/Portugal (2018). Atualmente é professora associada II do Instituto de Saúde Coletiva onde coordena o Programa de pós-graduação em Saúde Coletiva, sendo credenciada como docente permanente neste Programa e no programa de pós-graduação em Enfermagem/UFMT.
} 


\title{
The deviant body: birth experience of children with microcephaly
}

\begin{abstract}
It is appropriate to understand how people interpret and act on the birth of a child with microcephaly by Zika virus given its wide dissemination in the social environment, where information circulates that is constantly updated by new discoveries that still surround the puzzles of emergence and distribution of this problem. In these scenarios individual and collective experiences are mobilized, expressing complex experiences, especially when it involves physical disability, there is no possibility of cure and require efforts for continuous management.
\end{abstract}

Keywords: body; experience; microcephaly; Zika virus.

\section{El cuerpo desviado: experiencia de nacimiento de niños con microcefalia}

Resumen: Es apropiado comprender cómo las personas interpretan y actúan sobre el nacimiento de un niño con microcefalia por Zika virus dada su amplia difusión en el entorno social, donde circula información que se actualiza constantemente por nuevos descubrimientos que aún rodean los rompecabezas de la emergencia y la emergencia. distribución de este problema. En estos escenarios, las experiencias individuales y colectivas se movilizan, expresando experiencias complejas, especialmente, cuando se trata de discapacidad física, no hay posibilidad de cura y requieren esfuerzos para un manejo continuo.

Palabras clave: cuerpo; experiencia; microcefalia; virus Zika. 
$\mathrm{N}$ o Brasil o nascimento de bebês com microcefalia por Zika vírus (ZIKV) um arbovírus originário da África com rápida dispersão nas Américas, atingindo países e territórios que notificaram casos de transmissão por mosquitos, transfusão sanguínea e via sexual - alertou gestores e profissionais da saúde, sobretudo, repercutindo sobre a família (principalmente os pais) pelo surgimento de um agravo à saúde que ocorre no período da gestação, gerando deficiências, e que se desdobra nas interações e no cotidiano familiar (CRUZ, 2019).

Vários estudos têm discutido as repercussões das deficiências físicas causadas por malformações congênitas na vivência dos pais, inclusive nos casos de microcefalia, enfatizando o modo como estes significam e agem diante do diagnóstico e do nascimento de seus filhos (COSTA et al., 2018; FERRARI, ZAHER e GONÇALVES, 2010; GOMES, PICCININI, 2010; SANTOS et al., 2011), revelando a importância de compreender os aspectos mais subjetivos e contextuais que a permeiam - a experiência.

A experiência na vida cotidiana, ilustrada pelas diversas versões sobre os fatos e pela riqueza das histórias de vida, pode ser compreendida como o resultado de múltiplas vivências sedimentadas e condensadas em significados particulares e compartilhados, que, ao serem interpretadas, expressaram sentido para as pessoas que as vivenciaram (ADAM e HERZLICH, 2001).

De modo geral, existe a compreensão de que a experiência do parto é marcante e significativa para as mulheres (KITZINGER, 1987), capaz de alcançar as pessoas em seu entorno (familiares, profissionais de saúde etc.). O primeiro contato das mães com seus filhos se revela um momento especialmente marcante na experiência, esta última compreendida por Bondía (2002) como um "território de passagem" que toca as pessoas e que se transforma em elementos relevantes que se acumulam no "estoque de conhecimento" (SCHUTZ, 2012).

Velho (2003) complementa o sentido da experiência trazendo a noção de cultura - que valoriza, dentre outros elementos, a rede de significados e a percepção das diferenças de visão de mundo. A reflexão de natureza antropológica tem sido importante instrumento na defesa de um pluralismo sociocultural, valorizando a liberdade existencial dos indivíduos que transitam em diferentes domínios e mundos de significados (VELHO, 2003). No presente estudo, o trilhar investigado foi norteado pela seguinte pergunta: como os pais (homens e mulheres) interpretam e agem diante do nascimento de uma criança com microcefalia por ZIKV? Quais as matrizes de significados (elementos que compõem a experiência) sustentam tais ações?

\section{O trabalho de campo: escolhas teórico-metodológicas}

Trata-se de uma pesquisa qualitativa com abordagem compreensiva, inspirada em conceitos da Fenomenologia de Alfred Schutz (2012) e na noção de cultura em Velho (2003). Para isso, se propôs realizar a abordagem socioantropológica, que tem sido utilizada especialmente no campo da saúde, por estar aberta às outras racionalidades, fornecendo espaço para interlocuções entre os diferentes campos de conhecimento, em um cenário aberto e fértil às investigações (CANESQUI, 2015). 
Sob a perspectiva socioantropológica, as concepções individuais e coletivas sobre saúde/doença são atravessadas pela cultura em diferentes épocas e sociedades. Assim, almejou-se ultrapassar as dimensões subjetivas, permeadas do mundo estruturado social e cultural, balizado por aspectos objetivos, intersubjetivos, simbólicos e morais, repletos de significação, que "não descartam os indivíduos de carne e osso" (CANESQUI, 2015: 17), para analisar o pensar, o viver e o lidar com o corpo/deficiência através do ponto de vista dos sujeitos.

Sobre os participantes da pesquisa, sua seleção foi intencional, por meio de abordagem pessoal ou via contato telefônico: mães e pais de crianças diagnosticadas com microcefalia por ZIKV, perfazendo ao todo 11 participantes (o9 mulheres e 02 homens). Os critérios de inclusão foram: pais maiores de 18 anos e crianças em tratamento nos serviços de saúde de Cuiabá e Várzea Grande, Mato Grosso, Brasil.

O número de participantes deste estudo foi delimitado pela riqueza dos dados, compreendendo que uma amostra qualitativa ideal é aquela que reflete, em quantidade e intensidade "as múltiplas dimensões de determinado fenômeno e busca a qualidade das ações e das interações em todo o decorrer do processo" (MINAYO, 2017: 10).

Para a produção dos dados foi utilizada entrevista em profundidade, utilizando como instrumento um roteiro com questões norteadoras para que fossem apenas disparadoras. As entrevistas foram realizadas individualmente, variando o número de encontros nas residências de cada família (até três), no período de janeiro de 2017 a abril de 2019, sendo registradas em gravador de voz digital. Em seguida, procedeu-se a transcrição das falas dos depoentes na íntegra. Os dados produzidos foram armazenados no banco digital da pesquisa e identificados nos trechos de falas. As mães e os pais entrevistados receberam nomes fictícios para garantir o anonimato na divulgação dos resultados do estudo, bem como os nomes de profissionais e serviços de saúde citados.

Para a análise dos dados, optou-se pela técnica de análise de conteúdo, na modalidade de análise temática, conforme Minayo (2014), ancorada em Bardin (1979). Para a operacionalização da técnica foram seguidos três momentos da análise temática, a saber: pré-análise, exploração do material e o tratamento dos resultados obtidos.

Para a realização do presente estudo foram seguidos os princípios bioéticos previstos na Resolução no 466 do Conselho Nacional de Saúde (BRASIL, 2012a), aprovado pelo Comitê de Ética do Hospital Universitário Júlio Muller mediante parecer $\mathrm{n}^{0}$ 1.842.018 e CAAE $\mathrm{n}^{0} 59553716.9$.0000.5541.

\section{A deficiência e a microcefalia: reflexões sobre o normal e o patológico}

Certas reações/comportamentos podem ser observadas nas questões que envolvem a deficiência física, especialmente aquelas visíveis e expostas (como na cabeça - caso da microcefalia), identificáveis e corporificadas na aparência, na forma, no tamanho e funcionalidade, denunciando a diferença (BARSAGLINI e BIATO, 2015) - estigma. Nesse sentido, causam apreensão nos pais de crianças nascidas com microcefalia por ZIKV, trazendo consigo repercussões emocionais e sociais (COSTA et al., 2018; CRUZ, 2019).

Conceitualmente, o estigma não diz respeito a atributos fixos em si mesmos negativos, mas pela forma como são atribuídos os sentidos mais depreciativos em certas condições e em contextos bem específicos na interação social (GOFFMAN, 
2004). Logo, um "atributo que estigmatiza alguém pode confirmar a normalidade de outrem, portanto ele não é, em si mesmo, nem horroroso nem desonroso" (GOFFMAN, 2004: 6), mas se trata de uma característica diferenciada daquilo que poderia ser previsto para uma determinada pessoa, ou, nesse caso, para a chegada de um bebê na família.

Para Goffman (2004), o estigma é um tipo especial de relação entre atributo e estereótipo, podendo ser dividido em três tipos, dentre eles existem as várias deformidades físicas, que se aproximariam às consequências clínicas físicas e visíveis da Síndrome Congênita do Zika Vírus (SCZV) - termo este que abarca todas as manifestações clínicas causadas pela infecção congênita por ZIKV - com alterações neuromotoras, sensoriais e cognitivas. Em todos os tipos de estigma existem as mesmas características sociológicas:

um indivíduo que poderia ter sido facilmente recebido na relação social quotidiana
possui um traço que pode-se impor a atenção e afastar aqueles que ele encontra, des-
truindo a possibilidade de atenção para outros atributos seus. (GOFFMAN, 2004: 10)

Como consequência ao estigma, as crianças com microcefalia e SCZV poderiam sofrer vários tipos de discriminações, através das quais efetivamente, e muitas vezes, sem pensar, isto é, como um ato não intencional (GOFFMAN, 2004), dirigidas pelas mais variadas pessoas, inclusive aquelas que estão mais intimamente ligadas a elas - a família.

As atitudes estigmatizadoras de pessoas mais próximas e no entorno dos indivíduos estigmatizados, como os familiares das crianças afetadas, podem ser muito mais impactantes do que as atitudes de outras pessoas mais distantes ou sem proximidade alguma (LEE et al., 2005). Contudo, as adversidades impostas pela condição crônica, que envolve as deformidades físicas que a SCZV possa produzir, podem reconfigurar a longo prazo as expectativas e os projetos de vida das famílias afetadas, através de renegociações, decisões e iniciativas que abranjam as diferentes dimensões da vida (ADAM e HERZLICH, 2001).

Porém, ao nascer e ao longo de seu crescimento e desenvolvimento, as crianças com microcefalia relacionada à SCZV são parametrizadas como "não normais" ou não adequadas para o padrão de normalidade ${ }^{4}$, na perspectiva da avaliação biomédica (norma) utilizada pela Semiologia e Semiotécnica5 em Neonatologia e Pediatria.

O termo norma é originado do latim que significa esquadro, já o termo normal significa perpendicular. É normal aquilo que é como deve ser. Ora, a norma nada mais é do que aquilo que foi feito para endireitar, ou seja, retificar, tornar reto. E a normatização é o ato ou o efeito de criar ou estabelecer uma norma (CANGUILHEM, 2015). O contrário disso, o termo anormal é aquilo que foge à norma, que está irregular, que está torto, ou, como se pode dizer: "está fora dos padrões de normalidade” (CANGUILHEM, 2015). Logo, as crianças com alterações morfofuncionais (cabeça diminuída, alterações neurológicas), deficiências físicas e atraso de desenvolvimento são consideradas "anormais" pelo saber biomédico.

Para Georges Canguilhem (2015: 189), a identidade do normal e do patológico é afirmada a partir do conhecimento do normal, porém, "não se trata de uma

\footnotetext{
$4 \mathrm{O}$ termo padrão de normalidade é comumente utilizado na avaliação dos parâmetros antropométricos de crianças e adolescentes, utilizando escalas e gráficos estatísticos utilizados no Brasil e em outros países pelo mundo, para acompanhar o crescimento e desenvolvimento infanto-juvenil.

5 Semiologia e Semiotécnica são disciplinas dos cursos da área da Saúde que comparam os dados subjetivos e objetivos com a normalidade dos sistemas do corpo humano, utilizando, dentre eles, exame físico e avaliação de dados antropométricos em gráficos padronizados.
} 
relação de contradição e de exterioridade, mas de uma relação de inversão de polaridade. Depreciando tudo aquilo que a referência a ela própria impede de considerar como normal". Para esse autor, ao aplicar a doutrina fisiológica à patologia é verificado o modo como as alterações podem se desviar do estado normal para o estado anormal, como no caso da triagem logo ao nascer que é realizada para a verificação da microcefalia em bebês. Existem parâmetros definidos por meio de evidências técnicas científicas e estatísticas para avaliar se a criança está dentro ou fora do "padrão de normalidade" para o acompanhamento da medida do perímetro cefálico (PC) até os dois anos de vida (BRASIL, 2012b).

Nesse sentido, a distinção entre o normal e o anormal seria uma simples distinção quantitativa, se enfatizar os termos de excesso e falta (CANGUILHEM, 2015). Ou seja, o anormal - alterações morfológicas cranianas em bebês - é definido pela medida de PC que seja maior ou menor do que aquela que está indicada como adequada para a idade da criança, reconhecida pelo caráter normativo do que é considerado como normal - estabelecido por uma norma.

A reflexão de Canguilhem (2015: 50) sobre o sentido do normal traz a equivocidade que esse conceito recebe no campo biomédico. Para o autor, é a "vida em si mesma, e não a apreciação médica, que faz do normal biológico um conceito de valor, e não um conceito de realidade estatística". Especialmente no caso da microcefalia associada ao ZIKV, é necessário examinar esse conceito de valor que determina o ser doente, para que não seja pautada meramente pelas médias obtidas estatisticamente. Por isso, Canguilhem (2015: 124) propõe que

não devemos nos limitar a estabelecer comparação com uma normativa resultante de médias, mas, sim, de condições socioeconômicas, sociopolíticas, socioeducativas, sócio-históricas, entre outras, juntamente atrelando com as condições individuais do examinado.

Por esse motivo, deve-se levar em conta tais condições individuais, pois há bebês com microcefalia que não são, necessariamente, acometidos pela SCZV, sendo também verdadeiro o contrário (CRUZ, 2019). Além disso, quando são ponderadas as deformidades e a deficiência física em decorrência da microcefalia e da SCZV, não seria absurdo considerar essa condição crônica de vida como normal.

Seria absurdo, porém, considerar esse normal idêntico ao normal fisiológico, pois trata-se de normas diferentes. Não é a ausência de normalidade que constitui o anormal. Não existe absolutamente vida sem normas de vida, e o estado mórbido é sempre uma certa maneira de viver. (CANGUILHEM, 2015: 92)

Compreende-se o corpo como um fundamento de inserção no mundo. Sob a perspectiva fenomenológica, o corpo é o entrelaçamento entre o que natural e o que é cultural, desempenhando um papel fundamental de estabelecer a relação com o mundo (ALVES, 2006). A deficiência poderia, então, ser compreendida como mais uma das formas corporais de estar e pertencer ao mundo.

Além disso, é preciso refletir sobre as noções de corpo (adulto ou recém-nascido), que devem ser ponderadas para além da constituição biológica mais explícita (visível) e abarcar a conjugação de elementos que sofrem ação dos processos de modelação cultural. Nesse movimento, o corpo em cena pode assumir e revelar distintos significados nos mais variados espaços sociais e em diferentes épocas (LE BRETON, 2007), revelando seu caráter sócio-histórico, cuja dimensão é estruturante.

Nesse sentido, entende-se que as preconcepções esperadas no outro ou no corpo de outrem (características e atributos físicos) - a identidade social, são 
transformadas em expectativas normativas, em exigências apresentadas e conferidas rigorosamente (GOFFMAN, 2004), seja pelo saber biomédico, seja pelos saberes socialmente construídos, que circulam nas sociedades complexas, e podem ser manifestas/expressas em qualquer momento da relação, inclusive no parto e nascimento.

\section{Parto e nascimento: a microcefalia e o corpo desviante}

No caso da microcefalia por ZIKV, é possível conferir e classificar a anomalia (anormalidade) fetal desde a gestação pelo uso das tecnologias que avançam no escrutínio do corpo. Nesse sentido, o diagnóstico pré-natal serve como dispositivo que permite o controle das alterações que ocorrem no corpo dos bebês (malformações congênitas) focado nas intervenções tecnológicas (uso de equipamentos) (LÖWY, 2017) que afetam, de modo abrangente, a experiência dos pais não somente na gestação, mas, também capaz de repercutir no parto e no nascimento. Compreender esses efeitos e ponderá-los com os aspectos socioculturais, podem revelar como a experiência é moldada pelas interações sociais, tradições culturais compartilhadas, estruturas variantes na produção do saber/conhecimento e as relações de poder associadas a ela (CONRAD e BARKER, 2011).

Sobre os acontecimentos de maior registro no conteúdo das entrevistas, observou-se que os pais, principalmente as mães, relataram detalhes que marcaram o nascimento de seus filhos, dando ênfase aos aspectos relacionados às funções de vitalidade e ao formato da cabeça. Vale lembrar que nas situações relatadas já havia o diagnóstico intrauterino confirmado, nele as imagens e os dados técnicos que eram abstratos, até então, com o nascimento ganharam concretude (materialidade), passíveis de verificação (ver, tocar, sentir). Nesse aspecto, o diagnóstico intrauterino antecipou certas expectativas em relação ao nascimento e passou ser averiguado, conferido e, em certa medida, relativizado pelas mães.

Nasceu bem, maravilhosamente bem, ele chorou, estava respirando bem, fez todos os
testes nele e não precisou ir pra UTI. Estava uma equipe de médico enorme dentro da
sala, porque, já sabia né, o médico já sabia, já tinha avisado que ele viria né, especial
e tudo. E aí ele nasceu com $2.600 \mathrm{~g}$, com $40 \mathrm{~cm}$ e o perímetro cefálico de $30 \mathrm{~cm}$ e a
nota Apgar dele foi 9. (Kátia, mãe de Guilherme, 2 anos)
[...] a Eloá nasceu super bem, por mais que a cabeça dela era menor do que a da
Camila, a Eloá nasceu com $26 \mathrm{~cm}$, a Camila nasceu com $28 \mathrm{~cm}$. (Samara, mãe de Eloá
e Camila, 3 anos)

Os aspectos relatados pelas mães dão destaque aos dados antropométricos dos bebês ao nascer (peso, altura, perímetro cefálico, escala de Apgar ${ }^{6}$ ). Esses dados correspondem à matriz do saber biomédico que estabelece parâmetros para a normalidade, remetendo a um conceito de valor baseado em curvas estatísticas, que avaliam o recém-nascido como adequado (ou não) para a idade gestacional. Todavia, nota-se que os parâmetros técnicos não foram suficientes para dizer que os bebês não estavam 'bem', trazendo, nesse sentido, uma visão da mãe mais ampliada do que a visão biomédica - reducionista.

Isso pode ser explicado pelo fato de que o diagnóstico (aquilo que classifica e rotula) é, na verdade, uma criação social, um processo interpretativo que se desdobra na interação social (JUTEL, 2009; 2011), e nele não se nega sua "realidade biológica em si”, mas implica em constatar que, antes mesmo de existir, ele pode

${ }^{6}$ A Escala ou Índice de Apgar é um teste que consiste na avaliação de 5 sinais objetivos do recém-nascido, atribuindo a cada um dos sinais uma pontuação de o a 2, em uma escala de o a 10, no primeiro e quinto minutos de vida. 
se tornar visível/tangível (ou não), problematizado e percebido de modo peculiar pelas pessoas ou grupos, como um elemento interligado aos costumes sociais, sendo influenciado por questões socioculturais e ganhando diversos significados.

Sob essa perspectiva, o que um grupo em particular - no caso, médicos especialistas fetais ou pediatras, considera problemático ou inviável, categorizado como muito abaixo da média (baixa expectativa), pode ser socialmente contingente para as mães. Isto é, não representa problema ou inviabilidade para elas, posto que o valor atribuído é dado à vitalidade dos bebês, como algo que lhes bastasse, sem necessidade de maiores aparatos e recursos tecnológicos para o viver.

A contraposição dos dados técnicos com a percepção das mães sobre o nascimento de seus filhos - que exibiram vitalidade, presença de reflexos e todas as condições clínicas esperadas para um bebê sem malformação congênita ou qualquer outro agravo - se reconhece na dissociação dos padrões estatísticos com a noção de doença. O que é ou não é um corpo doente está permeado por significados culturais e imprime sentidos existenciais - sistema simbólico ancorado em arranjos particulares (CONRAD e BARKER, 2011; LIRA, NATIONS e CATRIB, 2004).

De modo que, o diagnóstico pode fornecer uma expressão cultural do que uma determinada sociedade ou grupo social está preparado para aceitar como normal (JUTEL, 2011) e o que estes acreditam que deva ser tratado (medicalizado) ou que represente perigo à vida, representando um outro saber que deve ser valorizado.

$\mathrm{O}$ valor dado pelas mães para as condições de nascimento de seus filhos revela, também, um certo alívio pela baixa expectativa gerada no diagnóstico intrauterino de malformação fetal. Mesmo que, no saber biomédico, peso e altura do bebê sejam considerados pequenos para a idade gestacional e que 30 centímetros de perímetro cefálico, por exemplo, seja considerado abaixo do valor esperado para a idade, há um conhecimento construído ao longo do acompanhamento pré-natal que se mostra diferenciado (ressignificado), e que representa comportamentos e pensamentos singulares na experiência.

O componente cultural pode revelar o modo particular de como as noções sobre o corpo e a saúde são (re)elaboradas e (re)significadas em determinados contextos, marcando a experiência, como no nascimento de uma criança com microcefalia. De modo geral, nota-se que as diferentes realidades socioculturais exibem modos diferenciados de definir o que é normal e anormal, bem como do que é (ou não) um bebê saudável.

O mecanicismo da ciência biomédica, no contexto do nascimento, é o que vai definir o corpo como algo a ser medido, matematizado, parametrizado, onde a mentalidade fisiopatológica encontra sua lógica no uso dos recursos e aparatos tecnológicos, sob o pretexto de se obter um conhecimento objetivo e concreto (JARAMILLO e GUEVARA, 2017; LUZ, 2004). Mais do que isso, os estudos com base foucaultiana consideram o saber como uma forma de poder, no qual o saber especializado, que nessa perspectiva define a normalidade e a anormalidade humanas, tem sido a principal forma de exercer poder nas sociedades modernas (CONRAD e BARKER, 2011; FOUCAULT, 1977).

No entanto, contrapondo aos saberes preditivos da racionalidade biomédica, sob a perspectiva da abordagem da corporeidade, existe a premissa de que o corpo não é um objeto a ser estudado em relação à cultura, pois ele é o sujeito da própria cultura; ou seja, é construído através do que é aprendido, compartilhado e padronizado (CSORDAS, 2008; LANGDON e WIIK, 2010). Trata-se, portanto, 
de elementos sobre os quais as pessoas compõem significados para as suas ações interpretativas e práticas, concretas e temporais. Assim, a cultura abarca valores, símbolos, normas e práticas (LANGDON e WIIK, 2010).

Compreende-se, então, que o corpo é uma construção simbólica e não uma realidade em si, verificável apenas em função de suas métricas e dados técnicos, mas o efeito de uma elaboração social e cultural (LE BRETON, 2007) que envolve diversos saberes. Além disso, as coisas do mundo são investidas de um olhar, de um valor conferido pelos sentidos (LE BRETON, 2016).

É no corpo desses bebês, na forma como ele se exibe para os pais e para os profissionais, que se dá o julgamento de valor. Especialmente no caso da microcefalia associada ao ZIKV, é necessário examinar esse conceito de valor atribuído ao corpo da criança e que determina o ser (ou não) doente, pois ele define o normal e o patológico, a regra e o desvio (CANGUILHEM, 2015) - o corpo desviante, balizado pelo discurso médico que constrói esse saber/poder, capaz de influenciar os comportamentos das pessoas, impactar suas experiências e legitimar intervenções médicas (CONRAD e BARKER, 2011; FOUCAULT, 1977).

Assim, as noções e comportamentos ligados aos processos de saúde e de doença, e que também demarcam as fronteiras do normal e anormal, integram a cultura de grupos sociais onde os mesmos ocorrem, vertendo-se em lógicas singulares e particulares, como as que se apresentaram nos relatos dos pais. De modo que, se pode compreender que os contextos socioculturais, onde cada biografia se inscreve, modelam as necessidades, bem como, as características biológicas e corporais (LANGDON e WIIK, 2010). Estas não são universalizantes, pois podem distinguir-se devido a heterogeneidade cultural nas sociedades complexas, entendida como a coexistência de uma pluralidade de tradições culturais oriundas de diversas bases (VELHO, 2003).

Nesse sentido, admite-se que nas sociedades complexas podem coexistir diferentes estilos de viver e de ver o mundo, e que também, pode se dizer, de "ver o corpo". Todavia, nota-se que, mesmo considerando uma certa variação individual (VELHO, 2003), há um sistema compartilhado de valores e crenças que operam na experiência. Em se tratando do nascimento de bebês com microcefalia, existe a centralidade da atenção dos pais para a cabeça, atribuindo certo valor e significado da aparência desde a gestação.

Como em outras condições que envolvem doenças e deficiências físicas estigmatizantes, a atenção voltada para cabeça do bebê pode ter "conotações metafóricas" (CONRAD e BARKER, 2011). A cabeça é valorizada pelos saberes leigos e médicos como o comando central da vida, onde se localiza o cérebro - um órgão importante e delicado, sede da mente, do juízo, dos nervos e da razão, que pode se contrastar com outras partes nobres do corpo mais relacionadas ao fluxo vital, como as estruturas sanguíneas, por exemplo, o coração. Em todos estes, no entanto, existem significados culturais peculiares embutidos, que apresentam diversas respostas sociais.

Para os pais que receberam o diagnóstico de microcefalia de seu(s) filho(s) durante a gestação há uma grande expectativa quanto ao primeiro contato físico com o bebê recém-nascido para contrastar o que foi imaginado/idealizado e o que se apresenta de modo real/concreto, uma ocasião oportuna para a checagem e verificação dos fatos, no qual se confere relevância à visualização da cabeça - com ênfase no formato, proporcionalidade e aparência: 
Minha maior vontade era ver o Matheus, porque eu precisava de entender como que era a cabeça do Matheus... aí eles enrolaram o Matheus todinho, a cabeça do Matheus, eu acho que eles estavam com muito medo de... eu não sei o que estava vindo antes do Matheus, porque eles estavam totalmente com medo, era assim muito... enrolaram a cabeça do menino inteirinha pra mim não ver, me mostraram só o rostinho dele. (Flávia, mãe de Matheus, 2 anos)

O sentido de ver (a visão) - que serve para os pais conhecerem como é o corpo do bebê, pode ser compreendido como um dos mais solicitados nas relações das pessoas com o mundo e com os outros (LE BRETON, 2016). Nesses casos, se vê para saber se realmente é (de fato microcefalia) e o que se quer ver não são os artifícios que possam encobrir, ocultar ou suavizar a forma ou a aparência (BARSAGLINI e SOARES, 2018), mas sim o retrato mais exato e a concretude do corpo, da cabeça. Nesse sentido, o olhar explora os detalhes e se fixa nas diferenças, em não familiaridades (LE BRETON, 2016), podendo suscitar nas pessoas as mais diversas reações.

Mais do que checar, o primeiro contato com o bebê é como um momento de confirmação (ou não) da microcefalia. Nele encontram-se repercussões emocionais que questionam, por exemplo, o diagnóstico pré-natal recebido ou pode mobilizar recursos e soluções para compreender a situação vivida. O emprego dos acessórios e artifícios nos recém-nascidos que, intencionalmente ou não, podem disfarçar a aparência (o uso de touca, enrolar numa manta, etc.), teriam sido utilizados pelos profissionais de saúde como estratégia para minimizar o impacto desse encontro (mãe/bebê), como também poderia ser empreendida pelas próprias mães ao sair do hospital e/ou no seu cotidiano, nos deslocamentos e espaços públicos, para encobrir/ocultar as marcas visíveis (GOFFMAN, 2004) da microcefalia.

A cabeça é uma parte do corpo que na cultura ocidental é muito exposta e quando existe algum tipo de "defeito" se torna imediatamente visível às pessoas. Nesse caso, a visibilidade é um fator crucial, pois chama atenção pela sua maior evidência e gera certas consequências nos contatos públicos - quando o estigma passa a ser conhecido. O corpo desviante é um poderoso atrativo de olhares e de comentários, capaz de gerar discursos e emoções (LE BRETON, 2007). Sendo assim, a estratégia de encobrimento/ocultação das partes do corpo estigmatizantes poderia tornar-se inevitável, intencionalmente ou não, como uma possibilidade de tornar o defeito menos visível ou mais discreto, na tentativa de passar por normal (GOFFMAN, 2004). No entanto, encobrir para não perceber pode ser não tão generalizável assim.

A chegada de um novo bebê e no primeiro contato os pais desejam vê-lo com bastante atenção. Contudo, as reações dos pais não são homogêneas, algumas delas causaram crises emocionais mais intensas, outras nem tanto, porém, ambas marcantes e descritas com muitos detalhes:

Quando ele [o pai] chegou no hospital, ele entrou aí ele viu o Guilherme e o Guilherme estava de toquinha. Aí ele viu o Guilherme e eu tirei a touca e aí quando eu tirei a touca pra ele ver a cabecinha do Guilherme, ele não aguentou, ele chorou muito [...] era muito visível. A cabeça dele era muito pequena, no osso da cabeça de trás, perto da nuca, tinha um osso, acho que uns 4 dedos, um palmo pra fora [...] tinha muita pele sobrando quando ele nasceu... não era muito cabeludo na cabeça, então dava pra ver bastante. [...] quando ele nasceu a primeira coisa que eu vi também foi a cabecinha e também foi um choque pra mim. Era muito pequenininha, muito pequena mesmo, essa parte da testa dele era reta, não tinha mesmo a testa. (Kátia, mãe de Guilherme, 2 anos) 
De modo geral, percebeu-se a relevância dada pelas mães à cabeça do(s) seu(s) bebê(s), especialmente, no modo que a descrevem, como os detalhes de sua proporção, reentrâncias e texturas; de como essa parte do corpo do bebê atrai o olhar e o toque. Apesar das idealizações e antecipações na gestação, o diagnóstico pré-natal é uma realidade abstrata para os pais e demanda certa concretude no momento do nascimento dos filhos, bem como na vida cotidiana, que passam a ser cotejados com a presença testemunhada, pela visão, pelo toque, pelo sentir das mães, que trazem na experiência seus significados, seus saberes.

Destarte, o parto e o nascimento se revelam uma experiência sensorial de amplos sentidos, que marca a transição da imaginação para a concretude. Sobretudo, para as mães não era suficiente apenas ver, mas tocar, apalpar a cabeça, observála sem acessórios, através da exploração do sentir, onde as percepções sensoriais podem compor os significados sobre o mundo (LE BRETON, 2016).

Os diversos sentimentos e comportamentos diante do corpo desviante (diverso) que envolve a deficiência física revelam, simultaneamente, as dimensões individuais e coletivas e a confluência entre os elementos naturais e socioculturais (BARSAGLINI e BIATO, 2015), que se reportam à prévia interpretação e classificação do corpo, gerando a mobilização de parâmetros sociais e morais ideais, variantes no tempo e no espaço, que bem podem ser compreendidos no conjunto das repercussões decorrentes da experiência.

A experiência foi sentida na proximidade, na pele, no tocar a cabeça do bebê, permitindo a materialidade das coisas no mundo, que implica na "ruptura com o vazio e a confrontação com um limite tangível" (LE BRETON, 2016: 207) e que confere sentido. Ou seja, os sentidos mediaram e conformaram a experiência das mães, eles deram concretude (ou não) às expectativas e antecipações da sua realidade vivida.

A expectativa quanto a aparência dos bebês é elaborada na gestação e transformada (reconfigurada) a partir do nascimento, do contato sensorial que a mãe tem com as características reais do bebê, mas também do vínculo (ou não) entre mãe-filho (FLECK e PICCININI, 2013; GOMES e PICCININI, 2010).

Além da expectativa da mãe e da família, também existe a expectativa dos profissionais de saúde ao nascimento do bebê que podem se contrastar com os achados concretos. Nesta checagem, as mães podem até se questionar se é realmente o seu bebê, diante de um saber preditivo (biomédico) e com poder de verdade que, em muitos momentos, não se sustentou:

\begin{abstract}
No ultrassom mostrava que a cabeça dela era muito pequenininha e quando ela nasceu até os médicos ficaram bem espantados, falou: "Nossa, a cabeça dela não tá igual no ultrassom, a cabeça é um pouco maior". Então ela nasceu com $31 \mathrm{~cm}$, a cabecinha dela, porque lá mostrava bem menor... aí assim, graças à Deus deu tudo bem, não ficou na UTI, nem nada. [...] então, a primeira coisa foi olhar a cabeça dela, eu olhei assim, mas era uma criança normal pra mim, não era assim como os médicos falavam: "Ah a cabecinha vai ser pequenininha". Não, foi totalmente diferente, cabeluda também, falei: "Nossa, essa menina é minha, mesmo? Tem certeza que é minha? Cabeluda demais”. (Sônia, mãe de Melissa, 2 anos)
\end{abstract}

São casos concretos como esses que circulam entre as pessoas, que respaldam certas expectativas e que justificam a esperança dos pais, apesar do diagnóstico pré-natal. Eles também podem ocorrer pela possível imprecisão dos exames no cotejamento técnico e fica claro que, efetivamente, podem ser insuficientes ou limitados. De tal forma que, revelam as contradições do saber biomédico preditivo, responsável pelos enquadramentos e pelas categorizações com poder de verdade incontestável, mas que não se sustentam ou se dobram diante de outros saberes.

Além do mais, é possível considerar um bebê nascido com microcefalia como 
normal. Tanto é que, a microcefalia é um aspecto objetivo que pode ser definido como uma variação individual dentro da diversidade biológica. Nessa lógica, Canguilhem (2015) já afirmava que diversidade não é doença e que o anormal não é patológico.

O tamanho da cabeça e sua aparência foram considerados secundários pelos pais quando comparados com o evento do nascimento e da vida, nesse sentido de normalidade, o valor mais desejado era a vida (CANGUILHEM, 2015). As falas abaixo se referem ao mesmo caso:

\begin{abstract}
Quando nasceu eu não olhava assim no berçário, pra mim era igual, pra mim sempre foi, eu não vejo até hoje diferença. A diferença que eu vejo é que ela tem as dificuldades dela, mas eu não vejo aquela imagem ruim que eu tinha. Não concretizou não. (Elvis, pai de Maísa e Guido, 3 anos)

Ela [a filha] vai ser especial, ela tem microcefalia, mas nós não nos apegamos tanto a isso não, porque a nossa questão era sobreviver [...] A nossa questão era eu e os três sobreviver, essa era a nossa luta. [...] Igual ele [Elvis] falou, pra mim é normal, a gente nunca viu essa diferença. Eu, nem minha mãe a que participou mais né?! A gente não... Tanto que meu pai não tinha coragem de ir dentro da UTI, daí quando meus filhos nasceram ele falou: "Ela tem a cabecinha pequena mesmo? Porque a gente vai lá só vê coisas ruins", daí a minha mãe [disse]: "não, a gente não vê a diferença”. (Taís, mãe de Maísa e Guido, 3 anos)
\end{abstract}

Nota-se que o saber preditivo biomédico, que se mostra em forma de diagnóstico-prognóstico, pode ser confrontado por duas coisas: imprecisão/imprevisibilidade e a abstração dos critérios técnicos. Nelas podem se demarcar as fronteiras do normal/anormal, de acordo as perspectivas (dos profissionais, dos pais - por exemplo). Portanto, existe um limite da predição biomédica, que pode, em certos casos, encontrar-se isolada, assim como há um limite da tecnologia e dos parâmetros combinados para a mãe (ou pais, familiares etc.), da forma como interpreta e age frente ao corpo do bebê. E esses elementos conjugados compõem a experiência.

Em outra situação de nascimento, mesmo com a suspeita de microcefalia relacionada ao ZIKV durante o acompanhamento pré-natal e a constatação de diminuição do perímetro cefálico ao nascer, o contraste e o impacto do bebê imaginado para o bebê real, tanto pelos pais, quanto pela equipe de saúde, foi atenuado devido as boas condições do nascimento, como a presença de reflexos sensoriais (choro, sucção etc.) e por alguma proporcionalidade (enquadramento) corporal do bebê:

\begin{abstract}
Meu sogro e minha sogra foi visitar um dia e falavam "Cadê o defeito delas? Elas não têm defeito", falei "Aí a cabeça delas". "Não, a gente vai arrumar uma cumbuquinha, bate assim e arruma." ... eles não tinham, acho que, noção da gravidade, mas eu tinha, porque eu pesquisava. (Samara, mãe de Eloá e Camila, 3 anos)

Chorou, a sucção foi boa, por isso que houve a suspeita, somente a suspeita. Não foi diagnosticado após o nascimento, somente com 4 meses, porque ela nasceu enxergando corretamente, ouvindo, sucção dela bem forte, ela chorou, não precisou ir pra UTI e aí por isso que demorou pra sair o diagnóstico dela. [...] ela nasceu com o perímetro cefálico de 29 centímetros e aí houve a suspeita da microcefalia, porém ela tinha o corpo proporcional [...] feito o exame e constou as calcificações no cérebro dela, mas aí foi investigando, investigando pra saber o motivo... aí, com o4 meses de vida dela foi diagnosticado microcefalia por Zika Vírus. (Roberta, mãe de Amanda, 2 anos)
\end{abstract}

Evidencia-se a existência da fronteira entre as noções do normal/anormal quando estas são pautadas por diferentes parâmetros e de forma isolada. Os dados técnicos científicos do corpo se tornaram imprecisos à observação/olhar dos 
pais e familiares; existiram diferentes soluções para a situação: de um lado o controle tecnológico mediado por exames, aparelhos e equipamentos - que fomentam o diagnóstico e prognóstico, com alto poder preditivo (LÖWY, 2017); de outro se arruma, se ajeita, se espera, se aceita - que provê meios naturais e imponderáveis.

No entanto, para os saberes há certos limites, inclusive para o saber biomédico (intermediado pela tecnologia), nele não existem garantias e há casos, como o descrito abaixo, em que a realização de exames como ultrassonografias no período pré-natal se esbarraram nessas fronteiras, não identificando na gestação quaisquer alterações fetais.

Foi a partir do parto, tinha se passado duas horas, me chamaram [os médicos] e já
me falaram [...] explicaram: "ó, sua bebê nasceu $1 \mathrm{~cm}$ a menos, então o normal era
pra ter nascido com $32 \mathrm{~cm}$, ela nasceu com $31 \mathrm{~cm}$, e a gente vai entrar com a investi-
gação de microcefalia" [...] Assim, então eu fiquei muito desesperada, fiquei nervosa,
meu leite não veio no primeiro dia porque eu fiquei nervosa... daí eu não tive o leite...
aí ela [a bebê] queria mamar, muito desespero, muito nervoso e no primeiro mo-
mento eu não aceitei, eu busquei: "Por quê? Por quê, meu Deus? Da onde?” Porque as
ultrassom [estavam] tudo certo... oito ultrassons! [disse atônita] (Laura, mãe de
Clara, 3 meses)

Ressalta-se um detalhe relatado acima: a diferença de 01 (um) centímetro do perímetro cefálico do bebê para o parâmetro técnico de normalidade, uma medida quantitativa que antecipou o problema-diagnóstico pelo saber biomédico e que não foi percebido pela mãe em seu primeiro contato com a filha. Percebeuse, no caso em tela, a força do diagnóstico nas práticas de saúde e na sociedade, que atua e se revela como "categoria, processo e consequência" (JUTEL, 2011). Como categoria remete ao ordenamento dos sinais (perímetro cefálico, por exemplo) verificados pelos profissionais de saúde, traduzido à classificação técnica; como processo, refere-se ao método de avaliação - cotejamento de testes e observação clínica, em que pesa a intermediação tecnológica do corpo; e como consequência, quando se volta às diversas repercussões para os envolvidos (pais, familiares, profissionais de saúde) - inclusive a sua contestação (ou não).

De fato, acerca das repercussões, o diagnóstico mostra-se como um problema (desordem) que em determinadas circunstâncias pode revelar a insuficiência de conhecimento à mão, capaz de mobilizar as pessoas (SCHUTZ, 2012), principalmente os pais, a buscar novas receitas práticas para lidar com o problema (LIRA, NATIONS e CATRIB, 2004; RABELLO, ALVES e SOUZA, 1999).

Assim, o diagnóstico de microcefalia por ZIKV, seja no período gestacional, seja no nascimento, pôde ser considerado uma ruptura do fluxo cotidiano da família, uma ameaça súbita aos projetos e idealizações tomados supostamente como certos, um evento que passou a exigir de cada pessoa ações que permitissem reconduzir sua vida cotidiana dentro de determinados padrões considerados aceitos, viáveis - de um modo mais prático, para resolver seus conflitos/impasses e normalizar a situação (LIRA, NATIONS e CATRIB, 2004; RABELLO, ALVES e SOUZA, 1999).

Ao mobilizar o conhecimento, as pessoas efetuariam determinadas associações com outras malformações congênitas mais recorrentes entre as gerações (apreendidas de experiências passadas) e que acarretam a deficiência física e mental; estas seriam percebidas como um "objeto tipificado" do meio social, que traz consigo um horizonte de experiências possíveis e contém referências de familiaridade correspondente (SCHUTZ, 2012), orientando, desse modo, suas ações (interpretativas e práticas).

No entanto, ressalta-se na noção schutziana o alerta de que as idealizações 
sobre o geral e as ideias empíricas possuem o caráter de um conceito aberto e, por isso, passível de retificação ou até mesmo, com capacidade de corroborar com as experiências futuras (SCHUTZ, 2012). E que, em muitos casos aqui observados, algumas situações atreladas ao diagnóstico de microcefalia sofreram ressignificação por parte dos pais, conforme a ponderação de outros elementos que compõem a experiência.

É o caso da noção de deficiência. Para muitas pessoas, e em determinados contextos marcados pela desigualdade, a deficiência pode ser significada como promotora de isolamento ou sofrimento - uma espécie de sentença biológica de fracasso (DINIZ, 2003). Para outras pessoas, nada mais é (ou se torna) que um diferente modo de vida - um modo de experimentar o corpo fora da norma biomédica (CANGUILHEM, 2009), a ponto de que não pese qualitativamente a diferença. Nesse último caso, busca-se uma normalidade situada, localizada, ainda que, em um quadro biológico persistente às possíveis intervenções (JUCÁ, 2007) e irreversível (incurável) - capaz de reinventar-se.

\section{Considerações finais}

É preciso salientar que o estigma conferido ao corpo deficiente (desviante), quer seja de crianças ou adultos, não se restringe a um determinado espaço ou grupos, pois pode se propagar em amplas direções e sentidos (atingindo os próximos e os distantes) - sendo influenciado pela norma internalizada que opera nas interações sociais (GOFFMAN, 2004), ou seja, o significado social de incapacidade não emana de si mesmo, mas sim da própria tessitura da vida cotidiana uma experiência social (CONRAD e BARKER, 2011).

A experiência é singular, portanto, não generalizável, contudo, permite apontar a existência de certas forças determinantes (elementos estruturantes) que atuam nos contextos que marcam o parto/nascimento dessas crianças, todavia, não se exclui a capacidade humana de poder (re)agir de forma mais ativa (questionar, denunciar etc.) a fim de provocar certas mudanças (GIDDENS, 2003) que gradativamente possam ocorrer.

O estigma pode ser menos generalizável do que o modelo proposto por Goffman (2004), pelo fato de que as pessoas podem estar mais preocupadas com a recuperação e o desenvolvimento das funcionalidades das atividades da vida diária, do que com as deficiências físicas e seus atributos depreciativos (ADAM e HERZLICH, 2001), e não se dobrar à estigmatização, possuindo consciência crítica, engajando-se em grupos de apoio entre seus pares e na militância pela causa em que está inscrita.

Portanto, acredita-se que nas situações que envolvem a deficiência na SCZV há a possibilidade das pessoas agirem de forma ativa e criativa. Porém, a ação não é pontual, ela estará sempre num fluxo contínuo (GIDDENS, 2003), visto que em certos casos de deficiência decorrente do ZIKV não se estabilizam de uma vez por todas, mas podem avançar, progredir e regredir, na mesma dinâmica que o corpo da criança está em constante variação. 


\section{Referências}

ADAM, P.; HERZLICH, C. Sociologia da doença e medicina. Bauru: EDUSC, 2001.

BARDIN, L. Análise de conteúdo. Lisboa: Edições 70, 1979.

BARSAGLINI, R.A.; BIATO, E.C.L. Compaixão, piedade e deficiência física: o valor da diferença nas relações heterogêneas. História, Ciências, Saúde-Manguinhos. Rio de Janeiro, 22 (3): 781-796, 2015.

BARSAGLINI, R.A.; SOARES, B.B.N.S. Impactos de adoecimento de longa duração: experiência de adultos jovens com Leucemia Mieloide Aguda. Ciênc. saúde coletiva, Rio de Janeiro, 23 (2): 399-408, 2018.

BONDÍA, J.L. Notas sobre a experiência e o saber de experiência. Revista Brasileira de Educação, 19: 20-28, abr., 2002.

BRASIL. Ministério da Saúde. Conselho Nacional de Saúde. Resolução CNS $n^{\circ}$ 466 de 12 de dezembro de 2012. Brasília, 2012a.

BRASIL. Ministério da Saúde. Saúde da criança: crescimento e desenvolvimento. (Cadernos de Atenção Básica, n. 33). Brasília: Ministério da Saúde, 2012b.

CANESQUI, A. M. (org.) Adoecimentos e sofrimentos de longa duração. $2^{\mathrm{a}}$ ed. São Paulo: Hucitec, 2015a.

CANGUILHEM, G. O normal e o patológico. 7 ed. Rio de Janeiro: Forense, 2015. CONRAD, P.; BARKER, K. K. A construção social da doença: insights-chave e implicações para políticas de saúde. Ideias, 3 (2): 186-220, 2011.

COSTA, E. S.; BONFIM, E. G.; MAGALHÃES, R. L. B.; VIANA, L. M. M. Vivências de mães de filhos com microcefalia. Revista Rene, 19 (e3453): 1-8, 2018.

CRUZ, G.V.S.F. "Microcefalia não é o fim”: experiência de famílias no contexto da condição crônica. Tese de Doutorado, Enfermagem, UFMT, 2019.

CSORDAS, T. A Corporeidade como um paradigma para a Antropologia. In: CSORDAS, T. Corpo/Significado/Cura. Porto Alegre: Editora da UFRGS, 2008. pp. 101-146.

DINIZ, D. Modelo social da deficiência: a crítica feminista. Série Anis, 28: 1-8, 2003.

DOMENACH, J. M. "La violencia”. In: JOXE, A. (orgs.). La violencia y sus causas. Paris: UNESCO, 1981. pp. 33-45.

FERRARI, S.; ZAHER, V.L.; GONÇALVES, M.J. O nascimento de um bebê prematuro ou deficiente: questões de bioética na comunicação do diagnóstico. Psicologia USP, São Paulo, 21 (4): 781-808, 2010.

FLECK, A.; PICCININI, C.A. O bebê imaginário e o bebê real no contexto da prematuridade: do nascimento ao $3^{\circ}$ mês após a alta. Aletheia, 40: 14-30, 2013.

FOUCAULT, M. O nascimento da clínica. Rio de Janeiro: Forense Universitária, 1977.

GIDDENS, A. A constituição da sociedade. São Paulo: Martins Fontes, 2003.

GOFFMAN, E. Estigma: notas sobre a manipulação da identidade deteriorada. $4^{\text {a }}$.ed. São Paulo, LTC, 2004. 
GOMES, A.G.; PICCININI, C.A. Malformação no bebê e maternidade: aspectos teóricos e clínicos. Psicología Clínica, 22 (1): 15-38, 2010.

JARAMILLO, N.; GUEVARA, J. El cuerpo evidenciado, el cuerpo dominado. Mecanicismo y medicina basada en la evidencia en relación al cuerpo, la anormalidad y la enfermedad. Teoria e Cultura, 11 (3): 41-54, 2017.

KITZINGER, S. A experiência do parto. Lisboa: Instituto Piaget, 1987.

JUCÁ, V.J.S. Compensação e estabilização: os substitutos da cura na saúde mental. Vivência, 32: 275-291, 2007.

JUTEL, A. Sociology of diagnosis: a preliminary review. In: MCGANN P.J.; HUTSON D.J. (orgs.). Sociology of Diagnosis. Bingley: Emerald; 2009. p. 03-32.

JUTEL, A. Putting a name to it: diagnosis in contemporary society. Baltimore: Johns Hopkins University Press, 2011.

LANGDON, E.J.; WIIK, F.B. Antropologia, saúde e doença: uma introdução ao conceito de cultura aplicado às ciências da saúde. Revista Latino-Americana de Enfermagem, 18 (3): 173-181, 2010.

LE BRETON, D. A sociologia do corpo. $2^{\mathrm{a}}$ ed. Petrópolis: Vozes, 2007.

LE BRETON, D. Antropologia dos sentidos. Petrópolis: Vozes, 2016.

LEE, S.; LEE, M.T.Y.; CHIU, M.Y.L.; KLEINMAN, A. Experience of social stigma by people with schizophrenia in Hong Kong. British Journal of Psychiatry, 186: 153-157, 2005.

LIRA, G.V.; NATIONS, M.K.; CATRIB, A.M.F. Cronicidade e cuidados em saúde: o que a antropologia da saúde tem a nos ensinar? Texto Contexto Enfermagem 13 (1): 147-155, 2004.

LÖWY, I. Imperfect pregnancies: a history of birth defects and prenatal diagnosis. Baltimore: Johns Hopkins University Press, 2017.

LUZ, M.D. Natural, racional, social: razão médica e racionalidade científica moderna. 2 ed. São Paulo: Hucitec, 2004.

MINAYO, M.C.S. "Ciência, técnica e arte: o desafio da pesquisa social”. In: MINAYO M.C.S.; DESLANDES, S.F.; GOMES, R. (ORG.). Pesquisa Social: teoria, método e criatividade. 30. ed. Petrópolis: Vozes, 2011. pp. 9-29.

MINAYO, M.C.S. O desafio do conhecimento: pesquisa qualitativa em saúde. 14. ed. São Paulo: Hucitec, 2014.

MINAYO, M.C.S. Amostragem e saturação em Pesquisa Qualitativa: consensos e controvérsias. Revista Pesquisa Qualitativa. 5 (7): 1-12, 2017.

RABELO, M.C.; ALVES, P.C.B.; SOUZA, I.M.A. (org.). Experiência de doença e narrativa. Rio de Janeiro: Editora Fiocruz, 1999.

SANTOS, S.R.; DIAS, I.M.A.V.; SALIMENA, A.M.O.; BARA, V.M.F. A vivência dos pais de uma criança com malformações congênitas. REME Rev. Min. Enfermagem, 15 (4): 491-497, out./dez., 2011.

SCHUTZ, A. Sobre a fenomenologia e relações sociais. Petrópolis/RJ: Vozes, 2012.

VELHO, G. Projeto e metamorfose: antropologia das sociedades complexas. Rio de Janeiro: Jorge Zahar Ed., 2004. 